\title{
Effect of variable winds on current structure and Reynolds stresses in a tidal flow: analysis of experimental data in the eastern English Channel
}

\author{
K. A. Korotenko ${ }^{1,2}$, A. V. Sentchev ${ }^{1}$, and F. G. Schmitt ${ }^{3}$ \\ ${ }^{1}$ Laboratoire d'Océanologie et de Géosciences, UMR8187, CNRS, Université du Littoral Côte d'Opale, Wimereux, France \\ ${ }^{2}$ P. P Shirshov Institute of Oceanology, RAS, Moscow, Russia \\ ${ }^{3}$ Laboratoire d'Océanologie et de Géosciences, UMR8187, CNRS, Wimereux, France
}

Correspondence to: K. A. Korotenko (kkorotenko@gmail.com)

Received: 8 May 2012 - Published in Ocean Sci. Discuss.: 13 June 2012

Revised: 18 October 2012 - Accepted: 1 November 2012 - Published: 27 November 2012

\begin{abstract}
Wind and wave effects on tidal current structure and turbulence throughout the water column are examined using an upward-looking acoustic Doppler current profiler (ADCP). The instrument has been deployed on the seafloor of 18-m mean depth, off the north-eastern French coast in the eastern English Channel, over 12 tidal cycles, and covered the period of the transition from mean spring to neap tide, and forcing regimes varied from calm to moderate storm conditions. During storms, we observed gusty winds with magnitudes reaching $15 \mathrm{~m} \mathrm{~s}^{-1}$ and wave heights reaching up to $1.3 \mathrm{~m}$. Analysis of velocity spectra revealed a noticeable contribution of wind-induced waves to spectral structure of velocity fluctuations within the subsurface layer. Near the surface, stormy winds and waves produced a significant intensification of velocity fluctuations, particularly when the sustained wind blew against the ebb tide flow. As during wavy periods, the variance-derived Reynolds stress estimates might include a wave-induced contamination, we applied the Variance Fit method to obtain unbiased stresses and other turbulent quantities. Over calm periods, the turbulent quantities usually decreased with height above the seabed. The stresses were found to vary regularly with the predominantly semidiurnal tidal flow. The along-shore stress being generally greater during the flood flow $(\sim 2.7 \mathrm{~Pa})$ than during the ebb flow $(\sim-0.6 \mathrm{~Pa})$. The turbulent kinetic energy production rate, $P$, and eddy viscosity, $A_{\mathrm{z}}$, followed a nearly regular cycle with close to a quarter-diurnal period. As for the stresses, near the seabed, we found the maximum values of estimated quantities of $P$ and $A_{\mathrm{z}}$ to be $0.1 \mathrm{Wm}^{-3}$
\end{abstract}

and $0.5 \mathrm{~m}^{2} \mathrm{~s}^{-1}$, respectively, during the flood flow. Over the storm periods, we found the highest unbiased stress values $(\sim-2.6 \mathrm{~Pa}$ ) during ebb when tidal currents were opposite to the southwesterly winds while, during the flood, the surface stresses slightly exceeded those estimated for a calm period. A comparison of obtained results gives a good agreement with those of other researchers working on direct measurements of turbulence in tidal flows.

\section{Introduction}

An understanding of turbulence and mechanisms of its generation in a tidal current are key goals of coastal physical oceanography, since turbulent processes are crucial in controlling flow dynamics and the vertical exchange of momentum and scalars within the water column. Knowledge of turbulence in shallow tidal channels is very important for making predictions about sediment and contaminant transports, vertical diffusion and bottom friction processes, as well as extremely important in modelling the mixing of oxygen, heat, nutrients and contaminants in the coastal ocean.

Hydrodynamic conditions at a shallow part of tidal channel as the Eastern English Channel (EEC) can vary from a relatively simple ebb-and-flood tidal system to a very complex one in which tide, wind stress, freshwater influx and wind waves have significant forcing effects on the system (Brylinski et al., 1996; Sentchev and Korotenko, 2004, 2005; Sentchev and Yaremchuk, 2007; Vantrepotte et al., 2007; 
Korotenko and Sentchev, 2011). Wind and wave drift currents are variable and can be either reinforced or interfered with tidal currents, dependent on the phase of a tidal cycle. Particularly during stormy conditions, flow patterns may be highly complex.

Since applying oceanographic ADCP (an Acoustic Doppler Current Profiler) measurements by Lohrmann et al. (1990), the Variance Fit method (VM) has been used successfully in a large number of studies of energetic tidal systems (Lu and Lueck, 1999a, b; Stacey et al., 1999; Rippeth et al., 2002, 2003; Fugate and Chant, 2005; Souza and Howarth, 2005; Nidzieko et al., 2006; Peters and Johns, 2006; Korotenko and Sentchev, 2011). However, in the presence of energetic surface gravity waves, the prediction of turbulent quantities with VM presents certain difficulties. The problem is that wind-induced waves can produce velocity variances of one order of magnitude larger than those associated with turbulence, and they often dominate the measured covariance between horizontal and vertical velocities. Since surface waves often occupy the same frequency range as marine turbulence, it is difficult to separate the latter from waveinduced velocity fluctuations using simple filtration. Therefore, development of various techniques and methods capable to remove the bias produced by surface waves from ADCP measurements of turbulent shear stress was an important issue over the past decade (Shaw and Trowbridge, 2001; Trowbridge and Elgar, 2003; Whipple et al., 2006; Feddersen and Williams, 2007; Rosman et al., 2008; Schmitt et al., 2009; Huang et al., 2010; Kirincich et al., 2010).

This paper addresses two challenges. Firstly, we perform a comprehensive study of velocity variations in the EEC, and spectral analyses of velocity fluctuations, during two typical periods (calm and storm conditions), and analyse the characteristic evolution of power density spectra in a wide frequency band. Secondly, we examine depth-time series of turbulent quantities in a tidal coastal flow, subject to wind forcing, in order to estimate its impact on turbulence variability throughout the water column in storm periods. In the paper, we present the ADCP observations of turbulence and its time-depth variability over twelve tidal cycles in a period of falling tide. Estimations of variance-derived RS, $P$ and $A_{\mathrm{z}}$ were corrected using the Variance Fit (hereafter VF) method to remove the wave-induced contamination of these quantities. We also scrutinise and compare the turbulent quantities for storm and calm periods.

The paper is organised as follows: in Sect. 2, we describe the region of interest, experimental settings, forcing and methodics of data processing. In Sect. 3, we synthesise and examine velocity spectra, turbulent quantities obtained with the use of the variance method, and scrutinise them for two forcing conditions. Conclusions are given in Sect. 4. In Appendixes A and B, we briefly describe the Variance and Variance Fit methods used for processing data.

\section{Region and forcing}

\subsection{Study area and ADCP deployment}

Velocity measurements were performed in the eastern English Channel (EEC), approximately $6 \mathrm{~km}$ offshore, northwest of the port of Boulogne-sur-Mer, France (Fig. 1). The study site, located in the south-eastern part of the Dover Strait, is characterised by a tidal range of $7 \mathrm{~m}$ and current velocity amplitude close to $1.5 \mathrm{~m} \mathrm{~s}^{-1}$ at spring tide and about $0.7 \mathrm{~m} \mathrm{~s}^{-1}$ during neap tide. Tidal currents have a predominantly semi-diurnal period with a pronounced fortnightly modulation due to interference of the major semi-diurnal constituents $\left(\mathrm{M}_{2}, \mathrm{~S}_{2}, \mathrm{~N}_{2}\right)$. A significant asymmetry of the sea-surface elevation curve in the study area revealed the contribution of higher order nonlinear harmonics $\left(\mathrm{M}_{4}, \mathrm{MS}_{4}\right)$, which also generated a larger velocity during the flood flow as compared to ebb (Korotenko and Sentchev, 2011).

A 1.2-MHz upward-looking four-beam broadband RDI ADCP was deployed on the bottom (18 m mean water depth) for a one-week period, from 9 to 16 June 2009, covering tide evolution from spring to neap. The instrument was operated in fast pinging mode 12 , providing one velocity profile per second. Each velocity record was an average of six short pulse measurements over a second interval. Velocities were recorded in beam coordinates with $0.5 \mathrm{~m}$ vertical resolution (bin size), starting from $1.5 \mathrm{~m}$ above the bottom (midpoint of the first bin). The ADCP was mounted in a $\pm 20^{\circ}$ gimbal to adjust for uneven bottom topography, although the instrument was slightly tilted $\left(1.25^{\circ}\right)$ with respect to the vertical. As was shown by Lu and Lueck (1999a), a $2^{\circ}$ tilt results in no more than a $17 \%$ bias in stress estimate for nonwavy conditions.

The orientation of the ADCP horizontal axes (heading) was chosen with respect to shoreline and dominant current direction (Fig. 1), so that the opposing beams 1 and 2, lying in the $x-z$ plane, allowed estimating the cross-shore component of current velocity and Reynolds stress. Beams 3 and 4, lying in the $y-z$ plane, on the other hand, allowed estimating the along-shore component of these quantities.

\subsection{Forcing: wind and wave data}

In subsequent analyses, we complemented velocity measurements by wind and wave data. Wind speed and direction were recorded at Boulogne-sur-Mer lighthouse (Fig. 1). Wave parameters (significant height, period, direction) were extracted from ADCP measurements and CEFAS WaveNet archive (2009). The closest buoy to the experimental site was located off Dungeness (the south-eastern coast of England), about $30 \mathrm{~km}$ northwest from the ADCP site (Fig. 1).

Figure 2 shows the wind record and time evolution of major wave parameters in response to wind forcing. Two different wind regimes could be identified during the period of ADCP measurements. Winds blowing from southern and 


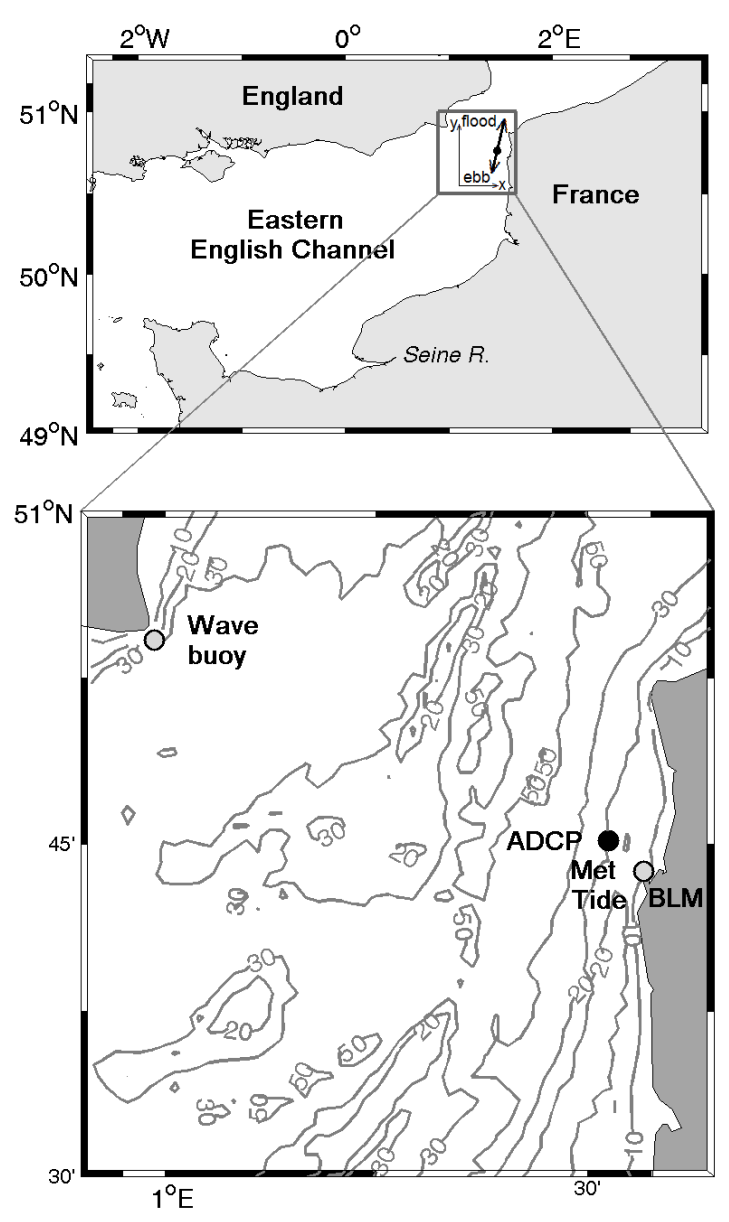

Fig. 1. The eastern English Channel (upper panel) and location of the ADCP deployment site (black circle) in the Strait of Dover (lower panel). Grey circles denote location of the CEFAS wave buoy, Boulogne-sur-Mer lighthouse and tidal gauge (BLM). The bottom topography is also shown. The $x-y$ plane and direction of ebb and flood flows are shown in the upper panel.

southwestern sectors, with moderate to strong speed (up to $10 \mathrm{~m} \mathrm{~s}^{-1}$ ), were dominant during the storm periods. Weaker winds $\left(\leq 6 \mathrm{~m} \mathrm{~s}^{-1}\right)$ from northern and northwestern sectors represented the second (calm) characteristic regime of the regional atmospheric circulation. Rapid changes in wind direction back and forth, occurring on a time scale of the order of a day, were a noticeable feature of the local wind variability. Calm and stormy weather conditions followed each other during the experiment. As seen, two calm periods were characterised by weak winds, were from northern or southern sectors and low waves, which significant wave height, $H_{\mathrm{S}}$, ranged from 0.3 to $0.6 \mathrm{~m}$.

As Fig. 2 shows, from two storm events the first one began at about 22:00 h GMT on 10 June, lasted slightly more than one day and peaked at the end of June 11 when $H_{\mathrm{S}}$ reached $1.4 \mathrm{~m}$. During 11 June, the average speed of a southwesterly wind reached $10 \mathrm{~m} \mathrm{~s}^{-1}$ while its gusts exceeded $15 \mathrm{~m} \mathrm{~s}^{-1}$.
These conditions caused the increase of the wave height from 0.3 to $1.4 \mathrm{~m}$. For the early hours of 12 June, both wind speed and the significant wave height dropped abruptly to $2 \mathrm{~m} \mathrm{~s}^{-1}$ and $0.3 \mathrm{~m}$, respectively. The evolution of the second storm event, on 15 June, followed a similar scenario: growing speeds of southwesterly gusty winds produced waves ascending from the west with the wave height exceeding $1 \mathrm{~m}$ by the end of the day on 15 June.

Comparison of $H_{\mathrm{S}}$ derived from ADCP pressure record, the SSH measured in Boulogne and the wave period $\left(T_{\mathrm{w}}\right)$ from CEFAS revealed a complex modulation of waves by tide and wind variability. During both storm periods, we could observe a significant decrease of the wave period $\left(T_{\mathrm{w}}\right)$ simultaneously with growing $H_{\mathrm{S}}$ as well as a modulation of $T_{\mathrm{w}}$ by tide and wind. For tidal conditions at the location of interest, waves induced by southwesterly winds propagated against the tidal current on ebb, their steepness and, hence, the occurrence of wave breaking increased. Therefore, we might expect larger intensity of surface turbulence on ebb than on flood. Note that according to our visual observations, about $40 \%$ of the sea surface were covered by 'white caps' during the storms.

Stratification. The observational period was characterised by a homogeneous distribution of temperature and salinity throughout the water column. Only during calm periods, a weak diurnal thermal stratification appeared in the upper $2 \mathrm{~m}$ layer principally on ebb or during current reversal.

\subsection{Methods of data processing}

The aim of this study is to investigate effects of wind and wave on tidal current, in particular their influence on spectral and turbulent structure of the current, looking at the vertical column turbulence through the relationships of the surface/bottom Reynolds stresses (hereafter RS), turbulent kinetic energy (TKE) production rate, $P$, and turbulent viscosity, $A_{\mathrm{z}}$, estimated with the Variance Method (VM).

During the measurements with ADCP, we obtained $1 \mathrm{cps}$ sampled velocity data that exhibited a wide range of time scales from high-frequency turbulent fluctuations to slow variations on time scales of the order of the record lengths (Fig. 5). To meet our goals, we implemented several methods of data processing that are itemised below:

1. We used a data inspection method (Sect. 3.2) to discard wrong data and interpolate data in case of short gaps $(<6 \mathrm{~s})$ discovered in the raw velocity records. As the inspection revealed, in the layer $\leq 12 \mathrm{~m}$ above the bottom (m.a.b), the data had no gap longer than $6 \mathrm{~s}$. All gaps discovered shorter than $6 \mathrm{~s}$ were linearly interpolated. No gaps were found below 11 m.a.b. during the calm periods. Such inspection was necessary for the use of the FFT method to obtain velocity spectra. 

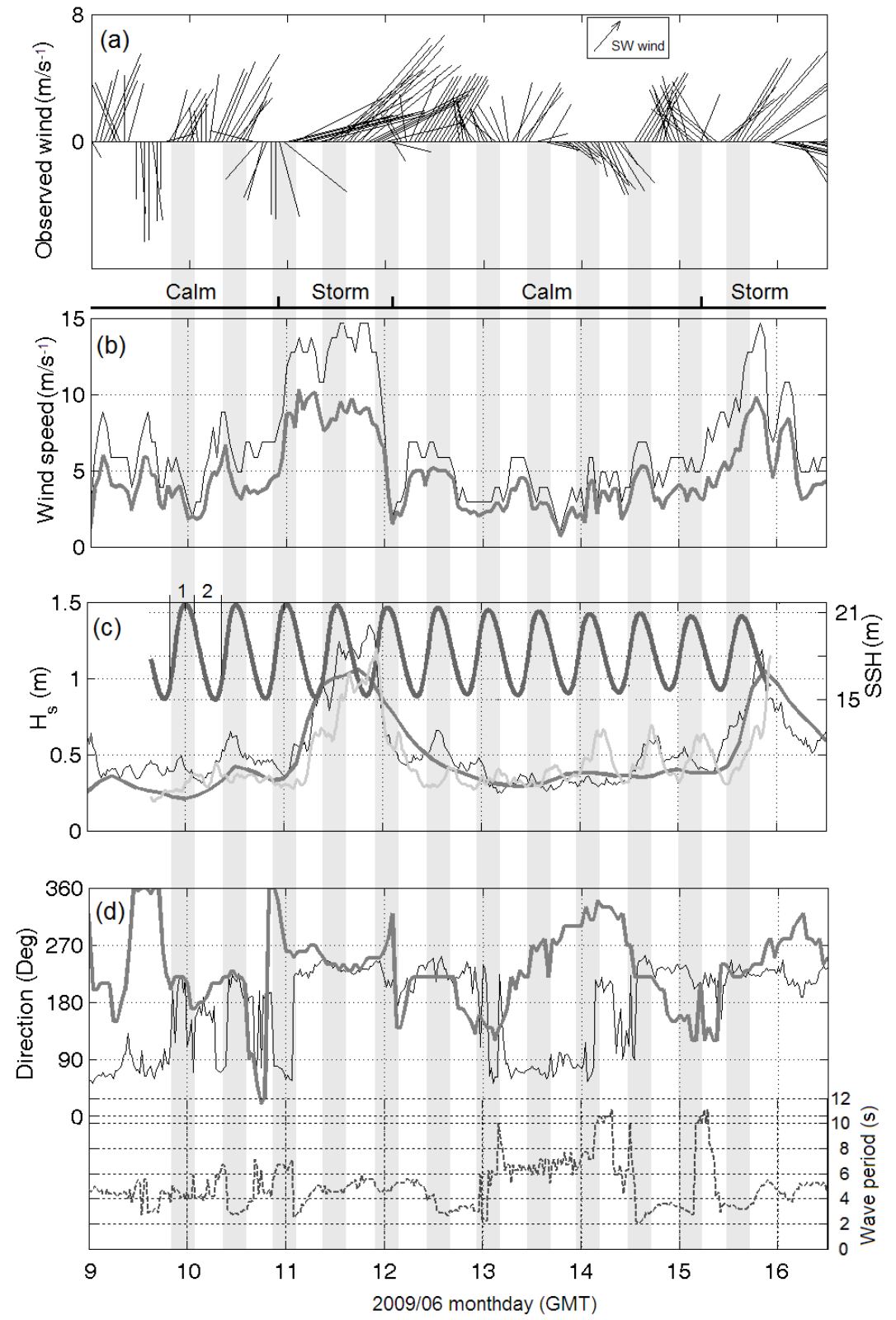

Fig. 2. Time series of (a) wind stick diagram, (b) wind gusts (black line) and averaged wind speed (grey line) (c), $H_{\mathrm{S}}$ observed by ADCP (grey line) and CEFAS buoy (black thin line), (d) wave (black line) and wind (grey line) directions, and wave period (dashed line) observed by CEFAS buoy. Two distinct storm events and calm periods, identified based on the wind speed and wave height records are annotated above the panel (b). In the panel (c), flood and ebb phases are indicated on the SSH line by 1 and 2, respectively and flood periods are shaded.

2. Following the method by Lu and Lueck $(1999 \mathrm{a}, \mathrm{b})$ we applied, for raw data, the low-pass and fourth-order Butterworth filter with a cut-off period of $20 \mathrm{~min}$ (Fig. 5) to separate the low- and high-frequency velocity components. The velocity components were used in the variance method (Appendix A) to estimate the Reynolds stresses and their derivatives.
3. A surface wave contamination is a significant source of error in methods for estimating Reynolds stresses including the variance method. A decontamination of wave-induced bias of the stresses is a serious problem in ADCP data processing. In our work, we use a method for separating wave and turbulent motions for use with the variance method by subtracting along-beam ADCP velocities over a specified separation distance after scaling to account for the decrease in wave orbital 

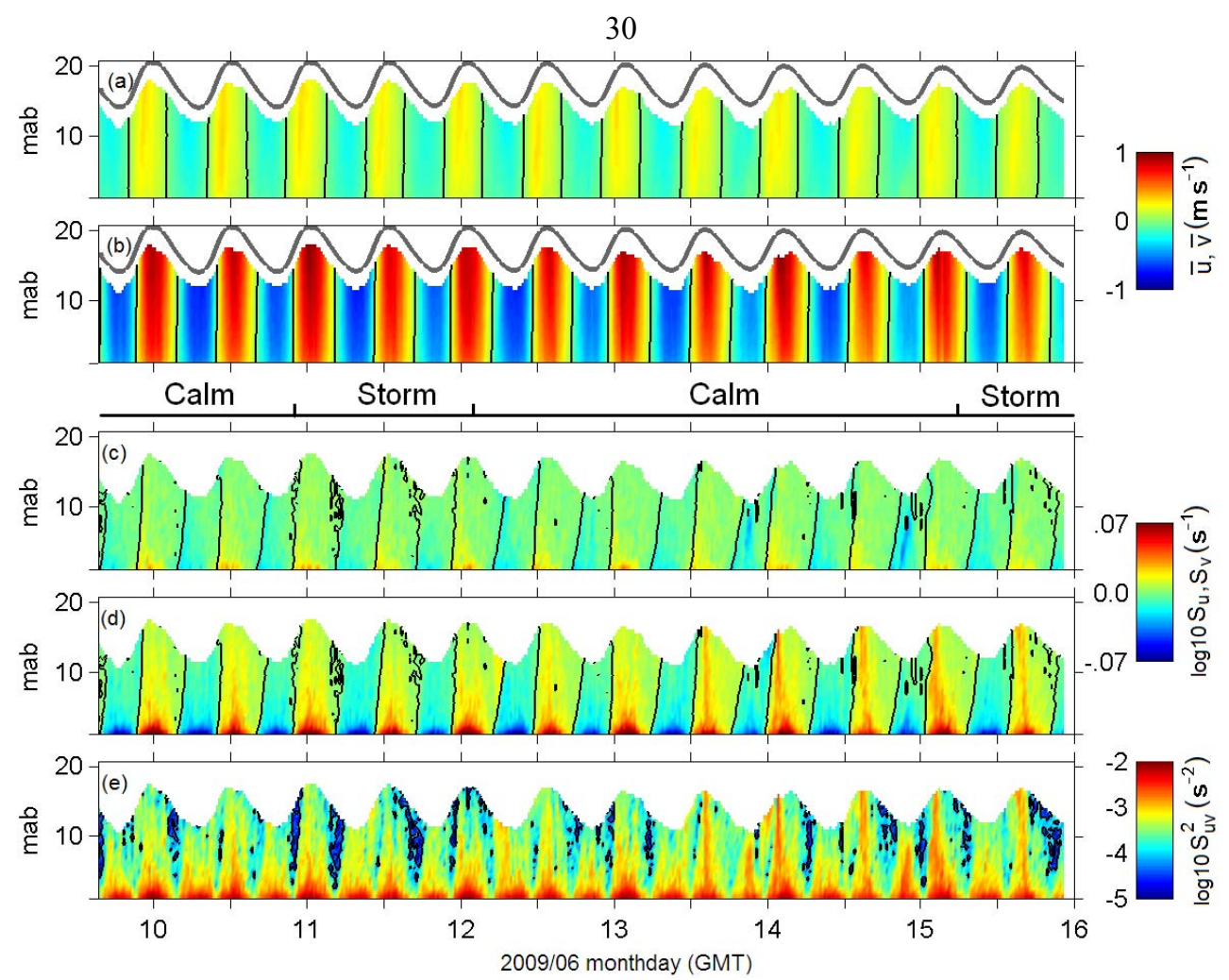

Fig. 3. Time-depth variability of (a) cross-shore mean current velocity $\bar{u}$ and (c) its shear $S_{\mathrm{U}}=d \bar{v} / d z$, (b) along-shore mean current velocity, $\bar{v}$ and (d) its shear $S_{\mathrm{V}}=d \bar{v} / d z$, and (e) shear velocity squared, $S_{\mathrm{uv}}^{2}$. Sea level is marked by a bold solid line over the velocity components. Zero-mean velocity and shear components are marked by solid lines. The abbreviation " $m$.a.b." denotes metres above the bottom. The storm and calm periods correspond to those indicated in Fig. 2.

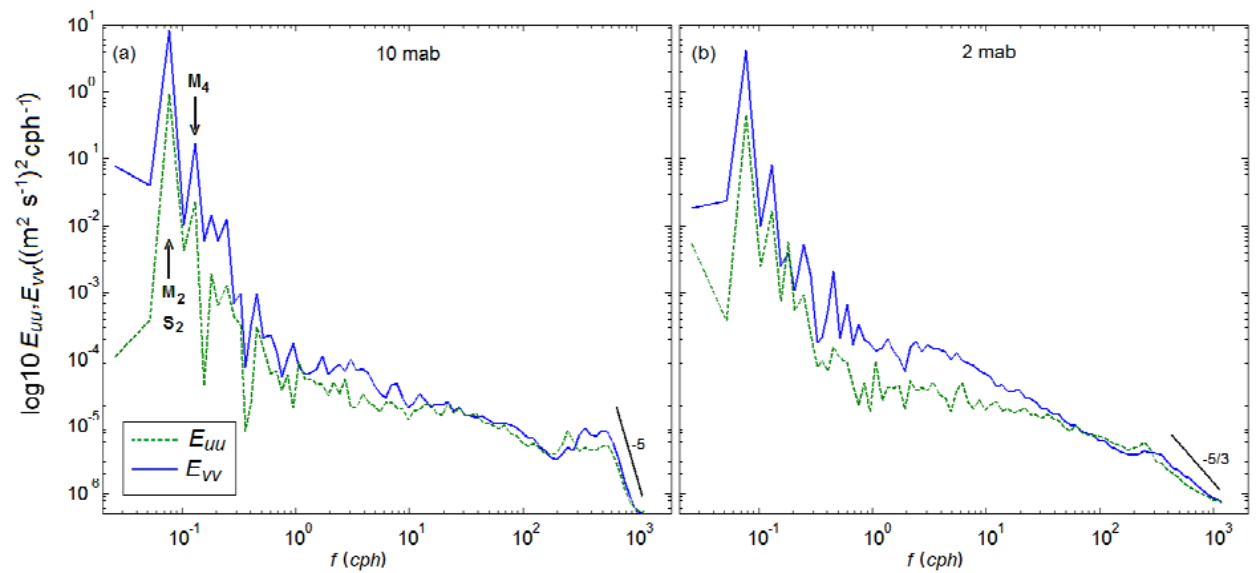

Fig. 4. Power spectral density for cross-shore $E_{\mathrm{uu}}$ (dashed line) and along-shore $E_{\mathrm{vv}}$ (solid line) components of the horizontal velocity at (a) 10 and (b) 2 m.a.b. computed for the second calm period. Solid black lines represent the $-5 / 3$ slope expected for an inertial subrange. Frequent tidal constitutions $\mathrm{M}_{2}, \mathrm{~S}_{2}$ and $\mathrm{M}_{4}$ are indicated against the corresponding peaks.

velocity with depth. This method, named the Variance Fit method, was proposed by Whipple at al. (2006). For our dataset this method allows removing the majority of the wave-induced contamination of the Reynolds stresses and their derivatives. Since the application of this method is not trivial procedure, we describe it in detail in Appendix B. 

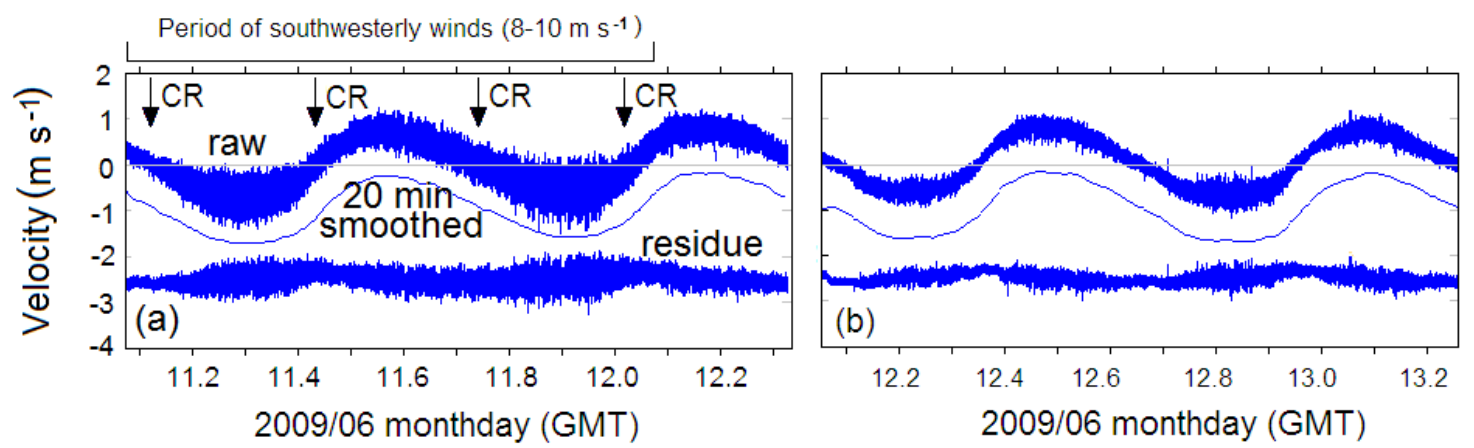

Fig. 5. 28-h samples of along-shore velocity at mid-depth (10 m.a.b.) during the storm on 11 June 2009 (a) and the calm period on 13 June 2009 (b). For the storm period, sustainable southwesterly winds were observed (the corresponding period is shown on the top of Fig. 5a). CR matches the current reversal. Negative velocity between two CR stands for ebb flow opposed to wind and wind-generated surface waves). Time is shown as a fraction of the day on $\mathrm{X}$-axis.

\section{Data analysis and discussion of the results}

\subsection{Time-depth variability of mean current and velocity shear}

A general description of the evolution of SSH and currents off the northeastern coast of France is important for a better understanding of water dynamics and tidal-generated turbulence. Tidal currents in the EEC are rather strong with velocity amplitude up to $2 \mathrm{~m} \mathrm{~s}^{-1}$ observed in the Strait of Dover during the primary spring tide (Sentchev and Yaremchuk, 2007). When the current was northward (with a small eastward component) the sea surface first rose, then dropped. The period of rising tide lasted less then that of falling tide (Fig. 3b). When the current was southward, the duration of rising and falling tide period was also different (Fig. 3b). A phase lag between sea surface evolution and currents makes it difficult to understand the tidal motions in the region. The west-east velocity component accounts for shoreward displacement of water and causes sea level to rise during the major part of the period (Fig. 3a). Therefore, this part of the tidal cycle (positive cross-shore velocity component) is referred to as flood tide. The seaward (negative) cross-shore velocity component marks the ebb tide. A peculiar feature of tidal dynamics in the EEC is the asymmetry of the SSH curve and current velocity with stronger currents occurring on flood, weaker on ebb, and high values of current acceleration observed during rising tide (Fig. 3b). Because of the strong asymmetry of the SSH curve, the period of falling tide exceeds that of rising tide by approximately $2 \mathrm{~h}$. Moreover, the tidal current lags the sea level by approximately $2.5 \mathrm{~h}$. Therefore, the surface current reversal (S-N component) occurred $2.5 \mathrm{~h}$ and $3 \mathrm{~h}$ before the arriving of the high water or low water, respectively, in Boulogne. A counter-clockwise veering of the current vector with depth could also be recognised in the point of the ADCP location. Note that ebb and flood periods could be easily defined using zero velocity contours in the field of the cross-shore velocity component shown in Fig. 3a.

Field studies by Prandtle et al. (1993) showed that, in the region of interest, the tidal transport was larger on flood than on ebb, so that there is a net residual transport to the northeast. In model studies, Sentchev and Korotenko (2005) showed that the predicted residual velocity of currents along the French coast ranged from $0.15 \mathrm{~m} \mathrm{~s}^{-1}$ at neap tide, to $0.25 \mathrm{~m} \mathrm{~s}^{-1}$ at spring tide.

Figure 3 shows the evolution of current velocity and velocity shear during the transition from spring to neap tide. The mean current velocity reached maximal magnitudes at the surface while the majority of the velocity shear was near the seabed. Figure 3 also revealed that along- and cross-shore components of velocities and their shears were tidally forced and exhibited semidiurnal variability. The along-shore velocity exceeded $1.1 \mathrm{~m} \mathrm{~s}^{-1}$ on the flood flow and $-0.7 \mathrm{~m} \mathrm{~s}^{-1}$ on the ebb flow, while the across-shore velocity component was much weaker and its magnitude did not exceed $0.4 \mathrm{~m} \mathrm{~s}^{-1}$. Note that storm periods could distinctly be recognised due to "knotted" lines of zero-mean shear of both components of current velocity (Fig. 3c, d). Velocity shears, during both storms, significantly decreased near the sea surface and they were gradually beginning to restore when winds ceased. This can be clearly seen from the sum of the velocity components shear squared,

$S_{\mathrm{uv}}^{2}=\left[\left(\frac{\partial \bar{u}}{\partial z}\right)^{2}+\left(\frac{\partial \bar{v}}{\partial z}\right)^{2}\right]$,

for three-day period following the first storm (Fig. 3e). During that period, the zero magnitude of $S_{\mathrm{uv}}^{2}$ appeared at the sea surface (the same for the second storm event), while during the calm period following the storm, the smallest magnitudes of $S_{\mathrm{uv}}^{2}$ were found only along vertical lines specifying time and position of the water slack, where current velocities and shears were weak. Hereafter, we conventionally refer to the 
water slack as a moment when a flow passes through a minimum.

\subsection{Velocity spectra}

For the analysis of velocity spectra, we used power spectral density obtained with a complex Fast Fourier Transform (FFT) with a Nyquist frequency of 0.5 cycles per second (cps). The essential requirement for applying a classical FFT method is the continuity of the data record. Therefore, the time series of the current velocity components were inspected for gaps in the initial $1 \mathrm{cps}$ sampled data. Data analysis revealed that, in the layer $\leq 12 \mathrm{~m}$ above the bottom (m.a.b.), the data had no gap longer than $6 \mathrm{~s}$, while all gaps discovered shorter than $6 \mathrm{~s}$, were linearly interpolated. This concerned only small amount of data $(<0.2 \%)$ with the majority of gaps detected during storm. No gaps were found below 11 m.a.b. during the calm periods. Further, the data in the upper layer (>12 m.a.b.) were excluded from spectral analysis as well as from estimations of turbulent quantities examined below.

Figure 4 shows the power spectral density of cross-shore, $u$, and along-shore, $v$, components, of the velocity vector at 2 and 10 m.a.b., recorded during the second calm period. Spectra of both components had a maximum at the semidiurnal cyclic frequency 0.08 cycles per hour (cph), while the diurnal, which peaked at $0.04 \mathrm{cph}$ was not clearly pronounced because of a short FFT-length. In the earlier field study, Korotenko and Sentchev (2011) showed that, in the EEC, the diurnal peak was of the same order of magnitude as the quarter-diurnal peak at $f \approx 0.16 \mathrm{cph}$ ( $f$ denotes frequency). At frequencies higher than $6 \mathrm{cph}$, spectral slopes varied between -1 and -5 . Figure 4 also indicates that in deeper layers, where the influence of wind waves were insignificant at frequencies $f>300 \mathrm{cph}$, the spectra were reminiscent of the inertial subrange with spectral slopes close to $-5 / 3$ (Fig. 4b). However, most slopes in the spectra presented departures from $-5 / 3$ (see discussion below). Recall that abovementioned examinations of raw data revealed that, below 11 m.a.b., the data had no gaps and, thus, the abovementioned the " $6 \mathrm{~s}$ " interpolation could not affect the spectra at high frequencies, for calm period shown in Fig. 4.

Analysis of spectra at 2 and 10 m.a.b. revealed that current velocity variations, at frequencies less than $0.5 \mathrm{cph}$, followed almost the same trend throughout the water column, indicating barotropic behaviour of the flow field. At frequencies $>0.5 \mathrm{cph}$, the spectra showed that the oscillations were intensified near the seafloor and expanded up to the mid-depth, indicating an energetic type of motion, controlled by the bottom boundary layer. Along-shore and cross-shore current spectra showed a different amount of energy at frequencies $<60 \mathrm{cph}$ throughout the water column, while at higher frequencies ( $>60 \mathrm{cph}$ ), the amount of energy was roughly the same. Figure 4 also shows that, in the frequency range 0.08 $0.3 \mathrm{cph}$, the power spectral density of both velocity compo- nents are reminiscent of a "red"-type spectrum, but was interrupted by the peak of energy at $0.5 \mathrm{cph}$, and a shoulder ranged between 0.8 and $10 \mathrm{cph}$. At frequencies $0.3-0.4 \mathrm{cph}$, the variance-preserving form of the spectra (not shown here) revealed a distinct energy gap lying between a low-frequency (barotropic) oscillations and a high-frequency turbulence interval.

Figure 4a shows the energy spectrum peaked at 300$600 \mathrm{cph}$ and represented by a bimodal structure that corresponded to waves with periods of about 5 and $10 \mathrm{~s}$. These wave periods have been also revealed from the data recorded by the CEFAS buoy. The longer wave period appeared to be associated with swell, because its energy decreased much slower with depth, as compared with wind-induced wave energy that fell abruptly with depth. As seen, either swells or wind waves, made a relatively small contribution to the power spectra, near the seabed.

\subsection{Comparison of spectra for storm and calm periods}

Before analysing and comparing velocity spectra for the storm and calm periods, we examined the structure of current velocity obtained with the ADCP. For the purpose of this paper, herein, we limited our attention to the first storm period and the calm period, following the storm, as they are shown in Fig. 2b. For both periods we assessed one-day-long time series of the along-shore velocity component at middepth, estimated from beam 3 and 4 data with resolution of $1 \mathrm{~s}$. In subsequent analysis, we adopted the strategy of Lu and Lueck (1999a, b). To estimate the Reynolds stress and their derivatives, we applied the low-pass and fourth-order Butterworth filter with a cut-off period of $20 \mathrm{~min}$ that allowed separating the low- and high-frequency velocity components and using the variance method (Appendix A).

Figure 5 allows comparing the along-shore velocity component for the first storm and second calm periods. The upper curve represents the raw data of six-ping averages collected every $1 \mathrm{~s}$. The middle curve is the same data with 20-min smoothing and offset by $1.0 \mathrm{~m} \mathrm{~s}^{-1}$. The lower curve is the alongshore velocity fluctuation formed by taking the difference of the upper two curves and offset them by $2.5 \mathrm{~m} \mathrm{~s}^{-1}$.

For both periods, the raw velocity time series exhibited a wide range of time scales from high-frequency turbulent fluctuations to slow variations on time scales of the order of the record lengths. As Fig. 5 shows, high-frequency velocity fluctuations varied in agreement with the low-frequency flow with a velocity minimum during the slack water periods. For the storm period, the raw and residue data indicated intensive velocity fluctuations associated with surface gravity waves that can be clearly seen in the spectra presented below.

The curves of velocity variation show that the magnitude of the along-shore velocity fluctuations was sensibly higher on ebb than on flood during the storm, despite the action of sustained southwesterly winds, as seen in Fig. 5a, spanning almost the whole storm period. At that time, strong 


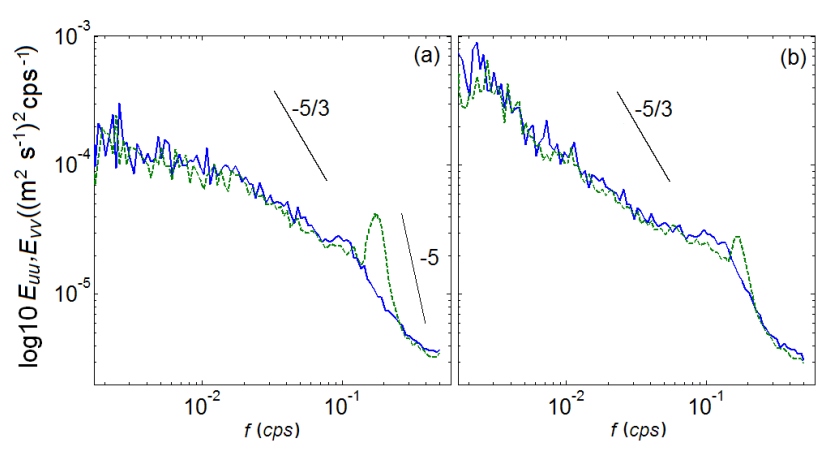

Fig. 6. Power spectral density of (a) cross-shore, $E_{\mathrm{uu}}$ and (b) alongshore, $E_{\mathrm{Vv}}$ components of velocity at 4 m.a.b. for calm (solid line) and storm (dashed line) periods as in Fig. 5.

wind blowing from the southwest (Fig. 2) acted against the current, modified the steepness of the wind waves, triggered wave breaking and, thus, increased the level of velocity fluctuations. The effect of such wave-current interaction, much stronger in the upper layer, is clearly seen at 10 m.a.b. (Fig. 5a). On the contrary, at the same depth level, during the calm period, the increase of velocity fluctuations was observed both on flood and on ebb (Fig. 5b). Higher amplitude of velocity fluctuations correspond to periods of strong tidal currents and high-level bottom friction generated turbulence in the flow. This major difference in magnitude of velocity fluctuations, during storm and calm periods, gives evidence to the effect of wave-current interaction in generating turbulence in the subsurface layer. The study of current effects on waves is very topical, especially in numerical wave modelling. The recent results of Ardhuin et al. (2012) clearly demonstrated a strong influence of opposed currents on waves through a modulation of the wave height by tidal currents, which results in rapid steepening of waves and enhanced wave breaking.

Figure 6 represents power spectral density of near bottom horizontal velocity components, estimated for the 28-h storm and calm periods shown in Fig. 5. To focus on the turbulent part of the spectra, they were plotted for the frequency range $>0.00167 \mathrm{cps}(\sim 6 \mathrm{cph})$ and presented in cps-scale for clarity. Note that the frequency range well above $6 \mathrm{cph}$ was similar to the inertial subrange of three-dimensional turbulence, even though its spectral slope was not exactly $-5 / 3$.

A comparison of spectra for both periods indicated characteristic discrepancies in the distribution of spectral energy, particularly in the level of spectral energy. This level is larger for the along-shore than for cross-shore velocity within the frequency band $0.00167-0.01 \mathrm{cps}$. In addition, the spectra for the storm period, were characterised by a sharp wave peak centred at $\sim 0.2 \mathrm{cps}(5 \mathrm{~s})$ and further above $0.2 \mathrm{cps}$ a spectral slope is close to -5 while, for the calm period, the spectra contained a broad, but poorly pronounced peak centred at $\sim 0.1 \mathrm{cps}(10 \mathrm{~s})$. Further above $0.2 \mathrm{cps}$, a spectral slope was close to $-5 / 3$. As seen, the wave energy, which penetrated in the near bottom layer, was lower than the energy of the underlying stress-carrying eddies which filled the range between 0.00167 and $0.05 \mathrm{cps}$ (i.e., between $1 \mathrm{~min} 30 \mathrm{~s}$ and $10 \mathrm{~min}$ ).

Departure from the slope of $-5 / 3$, at first glance, might indicate that there was no exact local isotropy (Tennekes and Lumley, 1972) in the turbulent flow we observed. Although, in our case, the departure might also be associated with the impact of wind waves, of which significant heights reached $1.3 \mathrm{~m}$ during storm periods. This impact would have been particularly pronounced near the sea surface and, thus, measuring velocities under storm conditions, the slope of the inertial subrange spectra would have been more affected by wave motion near the sea surface than in bottom layers, where one might have expected a well-pronounced inertial subrange spectra $f^{-5 / 3}$. During non-wavy conditions, the inertial subrange should have been pronounced in spectra throughout the water column. However, our results have shown that departures of the slope from $-5 / 3$, in the inertial subrange, were found for all computed velocity spectra and depended weakly on weather condition and depth. Such peculiarity of spectra within the turbulence interval is likely to be associated with a method used for processing velocity measurements obtained by ADCPs. Comparing velocity spectra computed for velocities measured by ADV and ADCP in the range $0.01-1 \mathrm{cps}$, Nidzieko et al. (2006) showed that ADV spectra always exhibited spectral decay, which closely followed the $-5 / 3$ slope. By contrast, the inertial subrange of three-dimensional turbulence was not readily seen in the ADCP spectra; within the same frequency range, the slope of ADCP (mode-12) spectra was close to - 1 . Peters et al. (2007) demonstrated that reducing ADCP instrumental noise could improve spectral shape in the inertial subrange.

To examine, in more detail, the response of currents to wind and wave forcing, we have estimated two-dimensional depth-frequency spectra of the along-shore velocity for the first storm and calm period on June 11 and 13 (Fig. 7). In order to adjust a colour palette and emphasise the wave peak, the spectra were presented for frequencies $f>0.4 \mathrm{cph}$. As seen, features of the spectra, for both periods, had a tendency to line up parallel to the depth-axis and the major energy containing band extended roughly up to $f \approx 5 \mathrm{cph}$ covering the entire water column. At the same time, Fig. 7 reveals significant differences in spectral energy distribution. The storm period was characterised by an amplification of energy throughout the water column with some gaps of energy at different depths. One of them, already mentioned above, was at $5 \mathrm{~m}$.a.b. between 0.4 and $0.5 \mathrm{cph}$. The calm period following the storm was characterised by a general attenuation of energy in the range from 0.4 to $20 \mathrm{cph}$ and some harmonics were significantly suppressed during a relaxation period after the storm. High-frequency margins of the energy-containing band, covering the range from $\sim 5$ to $11 \mathrm{cph}$ for both periods, showed that the spectral energy intensified toward the 


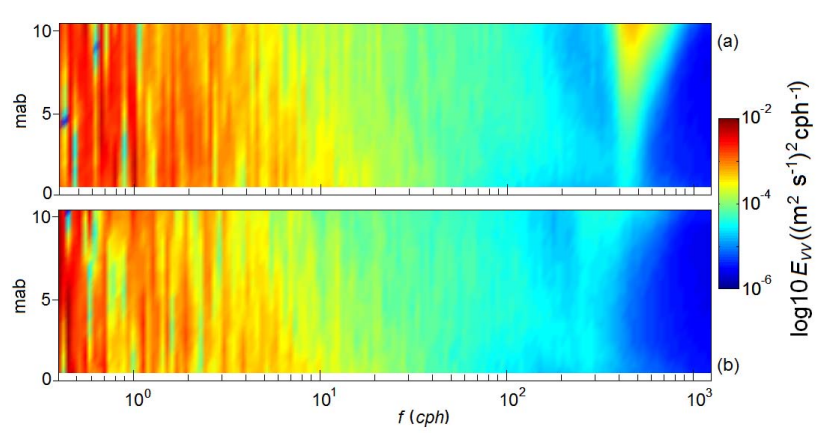

Fig. 7. 2D-power spectral density of the along-shore current velocity for (a) storm and (b) calm periods, as shown in Fig. 5.

seabed, which is a characteristic of wall-bounded turbulence. It is also remarkable that structures of the spectra, in the interval $40-110 \mathrm{cph}$, practically did not change, regardless of the intensity of wind and/or wave forcing.

Figure 7 also demonstrates distinct differences at highest frequencies for the storm and calm periods. During the storm, the spectrum, presented in Fig. 7a, indicated an energetic spectral peak associated with velocity fluctuation caused by wind action (wind waves, their breaking and instability of drift current). This peak, centred at $450 \mathrm{cph}$, covered the entire water column. During the calm period, spectrum in Fig. $7 \mathrm{~b}$ shows a weak wave peak at lower frequencies corresponding to velocity fluctuations generated by swells.

\subsection{Reynolds stress and mean velocity shear}

Current measurements revealed a complex structure of tidal flow in the shallow coastal zone, particularly when tidal forcing was accompanied by the action of variable winds and waves. To elucidate the combined effect of tides, winds and waves on turbulence variability in the water column, we begin from analyses of the structure and evolution of the Reynolds stress for the first calm and storm periods, as indicated in Fig. 2. Following Rippeth et al. (2002), we show in Fig. 8 vertical profiles of hourly averaged Reynolds stress, $\tau_{y}$ (row a), acting in the along-shore direction for each hour during one tidal cycle. To give a complete impression of the mean velocity, stress and shear variations over a semidiurnal cycle, together with the profiles of Reynolds stress, we show the along-shore components of the mean current (row b) and velocity shear, $S_{\mathrm{V}}$ (row c). All profiles were hourly averaged within a tidal cycle. For the shear (Fig. 8c), tic marks given along the horizontal axis correspond to a zero crossing of the profile in question. For an individual shear profile, the scale ranges from $-0.07 \mathrm{~m} \mathrm{~s}^{-1}$ to $0.07 \mathrm{~m} \mathrm{~s}^{-1}$ as indicated in Fig. 8c. The velocity profiles showed that, for both ebb and flood flows, the largest velocities were observed near the sea surface. Near the bottom, velocities had a logarithmic profile, which is distinctively seen for storm and calm periods, except during water slacks when the tidal current is weak.
The calm period. During the calm period, shear and most of the stresses, shown in Fig. 8 (left panel), have a tendency to decrease more or less regularly from extreme values near the seabed to lower values at the highest level observed $(\sim 5 \mathrm{~m}$ below the surface). However, some stress profiles greatly depart from this tendency indicating that besides the bottomshear production, other mechanisms appeared to contribute to the Reynolds stresses in upper layers.

Near the sea surface, despite the moderate forcing, a noticeable influence of wind and waves was clearly seen. Around slack water, the stresses and shears throughout the water column should be close to zero. However, as Fig. 8a indicated, stress profiles corresponding to the current reversal revealed more complicated, "curling back" structures, (e.g., profile 1 of $\tau_{y}$ in Fig. 8a) which were certainly associated with surface forcing and played a significant role during the weak flow period. The largest stress magnitudes and shear occurred at times of highest flow speeds. The stresses indicated a considerable asymmetry between the ebb and flood. During the flood, near-bed stress and shear exceeded $2.7 \mathrm{~Pa}$ and $0.08 \mathrm{~s}^{-1}$, respectively, at the time of maximum depth mean flow speed $\left(\sim 1.1 \mathrm{~m} \mathrm{~s}^{-1}\right)$. On ebb, the stresses and shear were limited to $\sim-0.8 \mathrm{~Pa}$ and $-0.07 \mathrm{~s}^{-1}$ during the peak ebb, when depth-mean flow was about $-0.7 \mathrm{~m} \mathrm{~s}^{-1}$. The magnitudes of stress and shear for different phases of tidal cycle in our study appeared to be very close to those estimated by other researchers (Lu and Lueck, 1999d; Rippeth et al., 2002; Seim, 2002; Wiles et al., 2006) for tidal channels and inlets.

The storm period. As was mention above, sustained winds blowing from southwest produced waves propagating in the direction opposed to the ebb flow. Such waves, due to a tendency to steepen, were able to break over the ebb shoal, dissipating energy in a subsurface layer and homogenising the latter. As was shown by Terray et al. (1996), the homogeneous sub-surface layer extends to $Z_{b}=0.26 K_{\mathrm{p}}^{-1}$, where $K_{\mathrm{p}}$ is the peak wavenumber of the local wind sea. In contrast, during flood flow, sea surface waves propagating with the currents were elongated and, hence, conditions for wave breaking became less favourable. As the consequence, during storm periods, particularly when the wind blows against the ebbing tide, we observed a significant enhancement of turbulence while, during the flood flow, turbulence generation near the sea surface was moderate. Earlier, a similar effect was reported by Seim (2002) and Rippeth et al. (2003).

Next, to illustrate the significance of wind and wave effects on the Reynolds stress, we present in Fig. 8a (right columns) the uncorrected along-coast stress. Below, we apply a method to eliminate wave-induced bias from the stress estimates. As seen, a comparison of the intensity of time-depth variations of the Reynolds stresses acting during calm periods revealed significant differences with those acting during the storm periods (cf. left and right columns of Fig. 8a). The main difference concerns the magnitudes of the Reynolds stress, which were much larger throughout the column during 

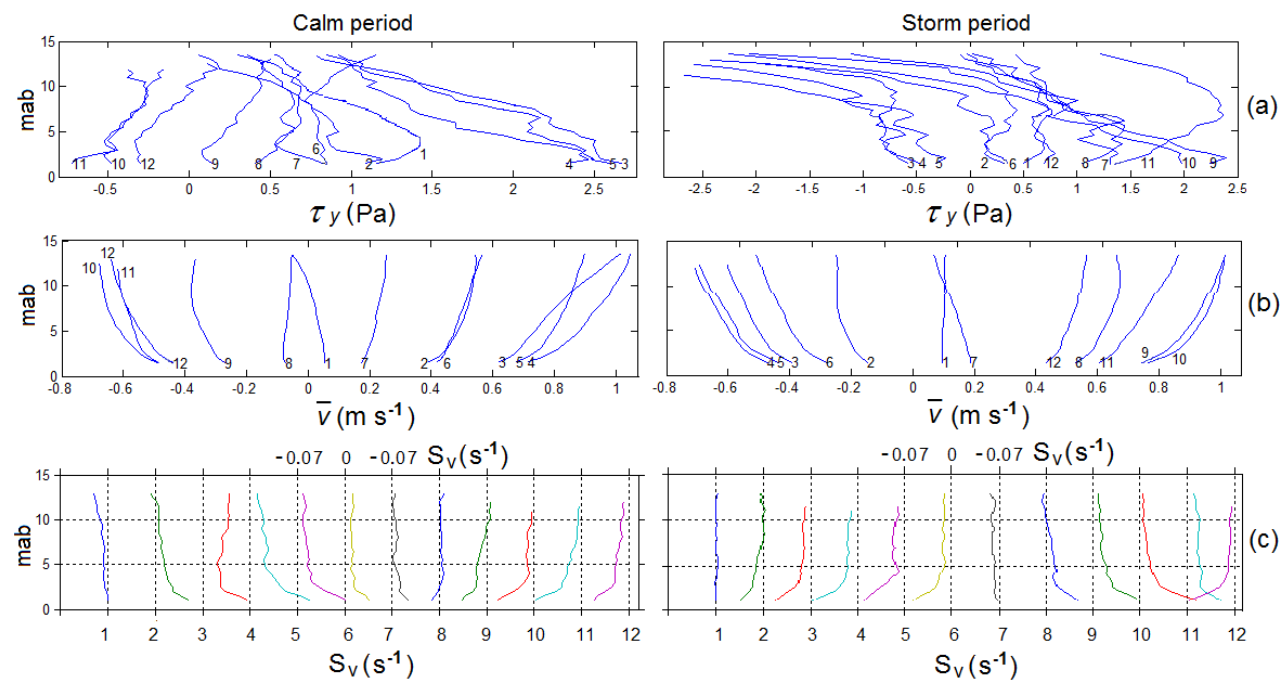

Fig. 8. Profiles of the along-shore mean velocity, $\bar{v}$, uncorrected Reynolds stress, $\tau_{y}$, and shear, $S_{\mathrm{V}}$ over a single tidal cycle during the calm (left side) and storm (right side) periods. Numbers indicate the sequence of the hourly measurements/estimations. Reynolds stress profiles averaged over each hour of the tidal cycle. For the shear (panel c), the scale is provided along the upper horizontal axis and ranges from $-0.07 \mathrm{~m} \mathrm{~s}^{-1}$ to $0.07 \mathrm{~m} \mathrm{~s}^{-1}$ for each individual profile. Vertical dashed lines correspond to a zero-crossing line for individual profiles.

the storm period than those estimated for the calm period. On the flood flow, above $\sim 7$ m.a.b., profiles of the "storm" stress indicated a distinct reversal tendency remaining positive. During the ebb, stress magnitudes, remaining negative, approached $-2.8 \mathrm{~Pa}$ at 12 m.a.b. revealing a strong combined effect of the wave-induced bias and shear-induced turbulence produced by storm in the sea surface layer.

\subsection{Time-depth variation of turbulent quantities}

Figure 9 shows the depth-time sections of the 20-min mean estimates of turbulent quantities computed by applying the variance method (see Eqs. A1-A3 in Appendix A) from which the wave-induced contamination were removed by use of the variance fit method (Appendix B). The presented results cover the entire period of measurements. It is obvious that computed stresses and inferred turbulent quantities are somewhat noisy and the right way to present them is to show composite patterns formed by averaging, for example, 4 tidal cycles as have been done by Peters (1997) and Rippeth et al. (2002). In our case, unfortunately, weather conditions were changing so rapidly that composite plots would not have been representative. Therefore, we have presented our results as they were.

Reynolds stresses. Plotted in the panels (a) and (b) of Fig. 9, wave-unbiased cross- and along-shore components of RS, show regular variation over 12 tidal cycles. During the flood, both stresses were positive (warm shading) and generally decreased with increasing height. During the ebb, both stress components were negative (cool shading) and their magnitudes, in the lower half of the water column, also decreased with increasing height above the bottom.
Above mid-depth, the along-shore stress frequently reversed its sign, corresponding to the sign reversals of the alongshore shear; good evidence of that was oblique contour lines during the period of current reversal. Similarly, to the alongshore stresses, the cross-shore stresses were smaller during the ebb flow than those during the flood.

Figure $9 \mathrm{a}$ and $\mathrm{b}$ indicate $\mathrm{a}$ significant increase of the stresses near the sea surface during the storm on 11 and 15 June 2009. It is interesting that the large stresses appeared during the entire period of the storms, but they were significantly enhanced when southwesterly winds blew during the ebb tide. Figure 10 illustrates this phenomenon by comparing the time-depth variability of the along-shore stress during the first storm under sustained southwesterly winds and the second calm under irregular moderate winds (lower panel) with the wind stick diagram (upper panel). As seen, near the surface, stresses became extremely large $(\sim-2.5 \mathrm{~Pa})$ during the ebb. Recalling that, for ebb periods, waves induced by southwesterly winds propagated against tidal current, their breaking, as was discussed above (Fig. 5), would enhance turbulence in the subsurface layer.

Returning to Fig. 9, note that it reveals a pronounced asymmetry of stress magnitudes between the ebb and flood. In calm periods, the stress cycle was seen to be highly regular and dominated by the along-shore component that exceeds $2 \mathrm{~Pa}$, while the cross-channel stress $\tau_{y}$ rarely exceeded a magnitude of $0.7 \mathrm{~Pa}$. Another aspect of asymmetry of the stresses is evident in their behaviour during successive water slacks. Around low water slack, the period of low stress $(<0.5 \mathrm{~Pa})$ lasted $\sim 2 \mathrm{~h}$ compared to $\sim 1 \mathrm{~h}$ around high water slack. 


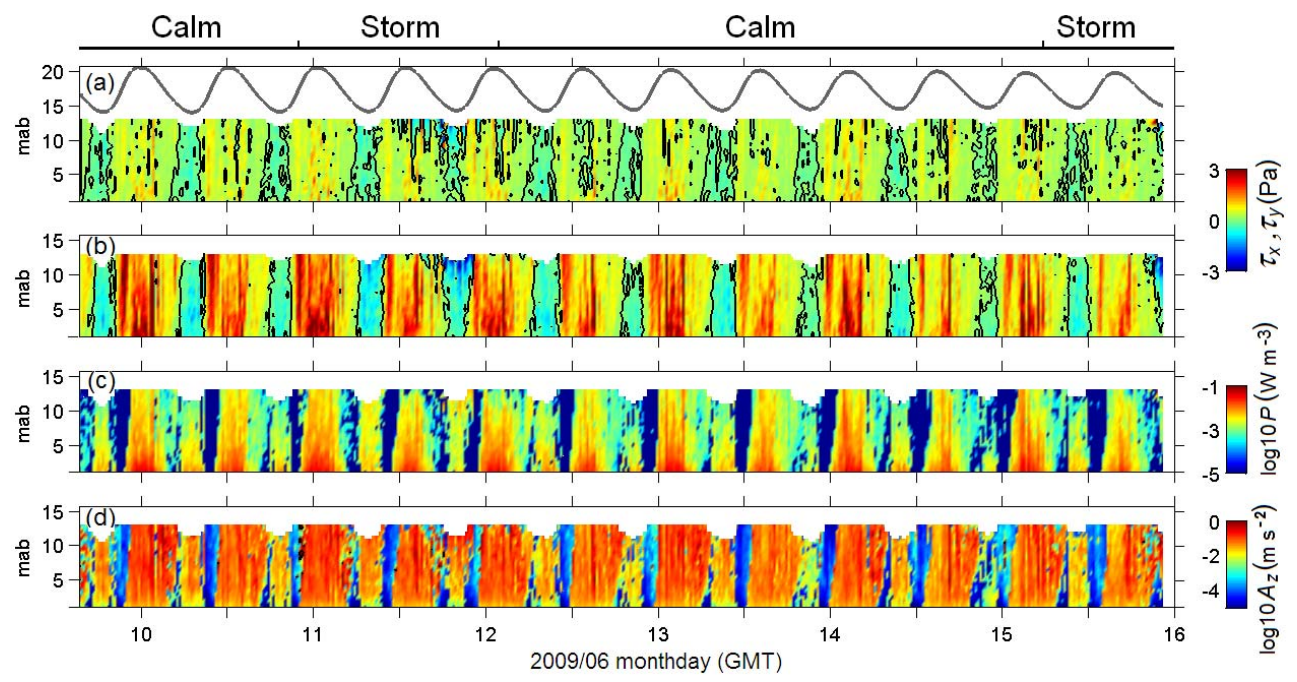

Fig. 9. Time-depth variations of the Reynolds stresses (a) $\tau_{x}(\mathrm{~Pa})$ and (b) $\tau_{y}(\mathrm{~Pa}),(\mathbf{c}) \log _{10} P\left(\mathrm{~W} \mathrm{~m}^{-3}\right)$ and $(\mathbf{d}) \log _{10} A_{\mathrm{Z}}\left(\mathrm{W} \mathrm{m}^{-3}\right)$ obtained from the variance method and corrected with VF method (Appendix B). The sea surface level (SSH) is shown in the upper panel. Zero-stress components (panels $\mathbf{a}, \mathbf{b})$ are marked by solid black lines.

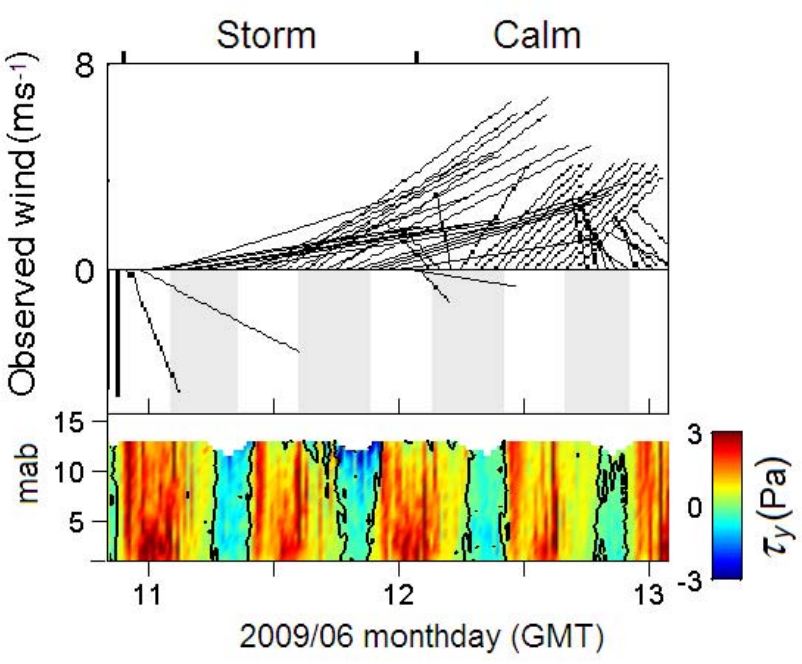

Fig. 10. Time series of wind (stick diagram - upper panel) and timedepth variations of the along-shore wave-corrected stress (lower panel) indicating a significant growth of turbulent intensity in the upper layer on ebb flow under southwestern winds during storm period. Ebb periods are shaded.

The near bottom RS and the mean tidal currents were highly correlated and near the seafloor, the stress exhibited a quadratic drag law behaviour. The drag coefficient, $C_{\mathrm{D}}$ strongly depended on the phase of the tide. For the alongshore velocity and stress, estimates of $C_{\mathrm{D}}=\tau_{y} /(\rho V \mid V) \mid$, based on the $10 \mathrm{~min}$ averaged full set of data, varied systematically between 0.0012 on ebb and 0.0022 on flood (Fig. 11). A comparison of our estimates of drag coefficient with those obtained by other researchers (Rippeth et al., 2002; Seim,

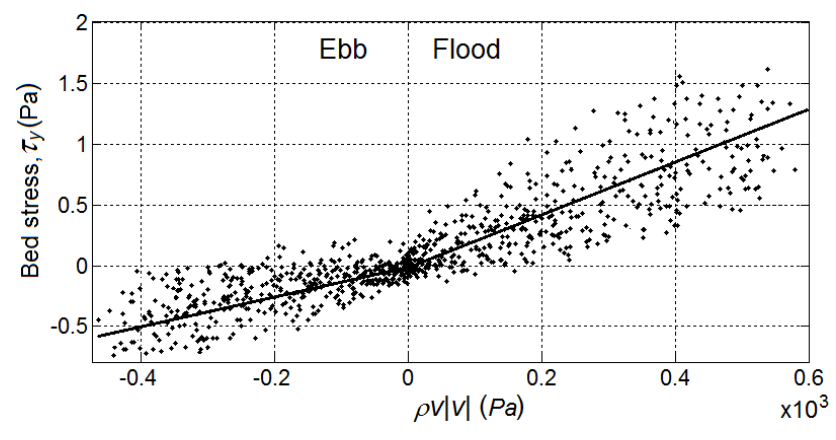

Fig. 11. Along-shore velocity squared at 2 m.a.b. versus Reynolds stress averaged within the bottom layer, 1.5-4.0 m.a.b. Both quantities are 10-min averaged. Linear fit for the flood flow yields a drag coefficient of 0.0022 , whereas for the ebb flow the fit yields a drag coefficient of 0.0012 .

2002; Howard and Souza, 2005; Willes et al., 2006) reveals a good agreement. For example, Seim (2002) found that $C_{\mathrm{D}}$ varied from 0.0013 to 0.0021 in a tidal inlet, which is very close to our estimates.

TKE production rate. Shown in Fig. 9c, the TKE production rate, $P$, was estimated from the product of the Reynolds stress and the velocity shear according to Eq. (A2). It indicates the amount of energy transferred from the mean flow to turbulent kinetic energy. In a tidal flow for non-wavy conditions, $P$ intensified toward the seabed, which is a characteristic of wall-bounded turbulence. The magnitude of $P$ spanned about four decades, ranging from about $10^{-1} \mathrm{~W} \mathrm{~m}^{-3}$ near the bottom to $\sim 10^{-5} \mathrm{~W} \mathrm{~m}^{-3}$ during weak flows. Note that either negative values of $P$ appeared due to round-off, or they were caused by unreliable stress estimates obtained 
during the turning of the tide. We, therefore, removed negative estimates of $P$, substituting them by the limit value of $10^{-5} \mathrm{~W} \mathrm{~m}^{-3}$, that is considered as the Doppler noise level for this quantity. The rate of TKE production was related to the magnitude of the current velocity and exhibited a dominant quarter-diurnal variation throughout the water column, with the exception of the uppermost layers, where strong wind and wave forcing can interact with the diurnal current muting the quarter-diurnal response. As with the stress, there was a clear asymmetry in $P$ between flood and ebb; for our deployment, the near seabed peak ebb value of $P$ was typically an order of magnitude less than that observed at maximum flood.

Similar variation of TKE production rate was documented by Rippeth et al. (2002) for a tidal channel. For spring tide, they found that the magnitude of $P$ spanned about five decades, ranging from about $1 \mathrm{~W} \mathrm{~m}^{-3}$ near the bottom to $\sim 10^{-5} \mathrm{~W} \mathrm{~m}^{-3}$ during weak flows while, for neap tide, it spanned four decades with a maximum about $0.5 \mathrm{~W} \mathrm{~m}^{-3}$.

Turbulent viscosity. The eddy viscosity coefficient $A_{\mathrm{z}}$, presented in Fig. $9 \mathrm{c}$, was calculated by dividing $P$ by the shear squared according to Eq. (3). The variations of $A_{\mathrm{z}}$ ranged from about $10^{-5} \mathrm{~m}^{2} \mathrm{~s}^{-1}$ during weak flow to $0.3 \mathrm{~m}^{2} \mathrm{~s}^{-1}$ during strong flow. Generally, the eddy viscosity increased with increasing height above the bottom in the lower half of the water column, and reaching a maximum near the mid-depth during calm periods. During the storm, the maximum of $A_{\mathrm{z}}$ moved upward and reached about $0.5 \mathrm{~m}^{2} \mathrm{~s}^{-1}$ at 12 m.a.b.

Here again, the magnitude and the range of variation of $A_{\mathrm{z}}$ in our study are found to be similar to estimates reported by $\mathrm{Lu}$ et al. (2000). In a tidal channel, the values of $A_{\mathrm{z}}$ varied from 0.3 to $10^{-5} \mathrm{~m}^{2} \mathrm{~s}^{-1}$ with a maximum at mid-depth.

\section{Conclusions}

We measured turbulence in the shallow water zone of the eastern English Channel with a bottom-mounted, upwardlooking, four-beam, 1.2-MHz ADCP RDI "Workhorse". The measurements performed over 12 tidal cycles covered the period of the transition from mean spring to neap tide. During the observations, we identified different forcing regimes based on the wind speed and direction and also wave height records.

To our knowledge, the present investigation of turbulence quantities and their evolution under tidal and unstable wind forcing is the first study conducted in the EEC, in its narrowest part - the Dover Strait. The water dynamics in this area is characterised by a pronounced asymmetry of tidal sea surface elevation and currents that echoes the evolution of turbulent quantities. Such pronounced asymmetry and large magnitude of current velocity appears to be associated with the unique geomorphology of the Channel and properties of tidal wave propagation. We limited our work to the presentation of the ADCP data, and straightforward processing of these data by means of spectral analysis and the variance method which al- lowed us to estimate RS, TKE production rate and turbulent viscosity. We have also applied the VF method in order to remove a wave-induced contamination of RS. Much attention was also paid to investigate the effect of unsteady winds on turbulent quantities.

The following summarises our results and demonstrates the effect of variable forcing regimes on turbulent quantities in a tidal flow along the northeastern coast of France. During the observation period, the weather conditions changed from calm to moderate storm regime with gusting winds reached $\sim 15 \mathrm{~m} \mathrm{~s}^{-1}$ and significant waves height of about $1.5 \mathrm{~m}$. During calm periods, wind speed and significant height did not exceed $5 \mathrm{~m} \mathrm{~s}^{-1}$ and $0.5 \mathrm{~m}$, respectively.

The recorded velocities exhibited both strong variations at tidal frequencies and high-frequency fluctuations. During the calm periods, the RMS velocity was found to be in the order of a few $\mathrm{cm} \mathrm{s}^{-1}$, and about a few tens of $\mathrm{cm} \mathrm{s}^{-1}$ during storm events. Shears have maximum values $\left(\sim 0.08 \mathrm{~s}^{-1}\right)$ near the bed, and decreased with height above the bottom. Above 5 m.a.b., the shear on the ebb flow extended to the surface during low wind forcing and was close to zero on the flood flow, but could be of either sign in the upper water column when the winds exceeded $5 \mathrm{~m} \mathrm{~s}^{-1}$. Southwesterly winds reinforced the flood tide shear, and decreased it in the upper water column during the ebb. It is remarkable that, during the strong wind and wave forcing, zero-mean magnitudes of shear squared $S_{\mathrm{uv}}^{2}$ appeared near the sea surface, indicating strong mixing, while during calm periods, such magnitudes were visible along vertical lines, specifying the moments of slack water.

In this paper, we paid much attention to analysis of the velocity spectra for both calm and storm periods. Generally, within the range between $0.08 \mathrm{cph}$ (semidiurnal tide) and $0.3 \mathrm{cph}$, velocity spectra were reminiscent of red-type spectra that were interrupted by a shoulder at $0.6-10 \mathrm{cph}$. In the variance-preserving form, spectra revealed a distinct energy gap at frequencies $0.3-0.4 \mathrm{cph}$ lying between lowfrequency barotropic and high-frequency harmonics. At frequencies $>0.3 \mathrm{cph}$, the spectra indicated several fully resolved maxima at energy-containing ranges, and a bimodal peak at the highest frequencies associated with contributions of surface waves. Within the spectral range from $0.6 \mathrm{cph}$ to $100 \mathrm{cph}$, the spectral slope was close to -1 while at the highest frequencies $(f \geq 500)$ the spectral slope, in the presence of waves, was close to -5 . Most of the spectra departed from the $f^{-5 / 3}$ regime, except at frequencies $f \geq 300 \mathrm{cph}$. For this frequency band, the spectra usually corresponded to the inertial subrange in the absence of surface waves. During the storm and calm periods, the spectral energy intensified toward the seabed within the band $5-11 \mathrm{cph}$, which is characteristic of wall-bounded turbulence. In the interval 40$110 \mathrm{cph}$, the structure of the spectra almost did not change, regardless of wind and wave forcing.

The variance-derived Reynolds stress was resolved from $1.5 \mathrm{~m}$ to $12 \mathrm{~m}$ height (mean depth was $18 \mathrm{~m}$ ). Most of the 
time, the stress was aligned with the current throughout the water column, except for slack periods when mean current and stress vectors greatly departed from each other. Stress magnitudes ranged from a detection threshold of $\sim 0.05 \mathrm{~Pa}$ to a maximum of $\sim 2.6 \mathrm{~Pa}$. For calm periods, we found that the Reynolds stress decreased more or less regularly from high values near the bottom by $70 \%-80 \%$ toward the top of the ADCP range. For the storm periods, the magnitude of the stresses first decreased from high values near the bottom toward mid-depth, and then increased again up to $2.8 \mathrm{~Pa}$ under the influence of wind and surface waves. The examination of the Reynolds stresses and shear profiles revealed that the near surface stresses were highest during southwesterly winds and peaked during the ebb. The rate of TKE production ranged from $\sim 10^{-1} \mathrm{~W} \mathrm{~m}^{-3}$ near the bottom to a detection threshold of $\sim 10^{-5} \mathrm{~W} \mathrm{~m}^{-3}$ during water slack periods. The bottom-generated turbulence extended to the near surface during the flood, but was typically located within the layer 1.5-8 m.a.b. during the ebb. However, during periods of strong southwesterly winds and breaking waves over the ebb shoal, we found that the TKE production rate increased near the sea surface. Generated near the surface and propagating downward, this turbulence merged the shear induced bottom turbulence propagating upward. For that reason, for periods of strong southwesterly winds, we observed high magnitudes of Reynolds stresses and TKE production rates throughout the water column. Estimation of the drag coefficient revealed strong dependency on the phase of tide. Its value varied between 0.0012 on ebb and 0.0022 during flood.

Finally, it is worth noting that the combination of ADCP measurements and wind/waves observations offers significant advantages for performing analysis of ADCP data, and allows interpreting the obtained results more correctly. Besides the study of turbulent quantities in the bottom boundary layer, we were particularly interested in comparing those computed for calm and storm events, since their time-depth variability reflected an unique interaction between winds, waves and tidal currents. We found that, for the storm periods, wave-unbiased turbulent quantities in the subsurface layer noticeably increased on ebb flow in cases when winds were from the southwesterly sector. During those periods, wind-induced waves propagated against the tidal current that caused wave breaking due to growing their steepness.

By contrast, on the flood, sea surface waves propagating with the currents were elongated and, hence, turbulence production due to the wave breaking mechanism appeared to be less likely than during the ebb. Similar effects of the windwave-tide interaction on the magnitude of turbulent quantities in the sea subsurface layer were observed by Seim (1992) and Rippeth et al. (2003). Note that during calm periods turbulent quantities indicate their decreasing away the seabed, which is a characteristic of wall-bounded turbulence.

\section{Appendix A}

\section{Variance method}

For the upward looking ADCP in a Janus configuration (Lu and Lueck, 1999b), a relationship between the velocity along the four beams, $V_{i}$ (positive toward the instrument) to those in Cartesian coordinates $u, v$ and $w$ allows inferring RS:

$$
\begin{gathered}
\tau_{x} / \rho=-\overline{u^{\prime} w^{\prime}}=\left(\overline{V_{2}^{\prime 2}}-\overline{V_{1}^{\prime 2}}\right) / 2 \sin 2 \theta, \\
\tau_{y} / \rho=-\overline{v^{\prime} w^{\prime}}=\left(\overline{V_{4}^{\prime 2}}-\overline{V_{3}^{\prime 2}}\right) / 2 \sin 2 \theta .
\end{gathered}
$$

Here $i=1-4$ represents the ADCP beam number, $u^{\prime}, v^{\prime}$ and $w^{\prime}$ are turbulent fluctuation components of velocity obtained after the decomposition of the raw velocity $(u, v, w)$ into a mean velocity $(\bar{u}, \bar{v}, \bar{w})$ and a turbulent part $\left(u^{\prime}, v^{\prime}, w^{\prime}\right), \theta$ is the half angle between opposing beams $\left(20^{\circ}\right.$ for the ADCP we used), and $\rho$ is water density. The overbar denotes a timeaveraged velocity at chosen interval $(20 \mathrm{~min})$. Note that to derive the mean velocity vector, we needed to assume that the mean flow was statistically homogeneous in the horizontal space over distances separating the beams, that is, $\bar{u}_{1}=\bar{u}_{2}$. To derive the Reynolds stress, it had to be assumed that all the second-order moments of turbulent velocity fluctuations were horizontally homogeneous, that is, $\overline{u_{1}^{\prime 2}}=\overline{u_{2}^{\prime 2}}, \overline{u_{1}^{\prime} w_{1}^{\prime}}=$ $\overline{u_{2}^{\prime} w_{2}^{\prime}}$, etc.

In Eq. (1), we omitted the terms describing noise errors due to pitch and roll of an ADCP. As was shown by Lu and Lueck (1999b), and Peters and Johns (2006), the contribution of such terms could be neglected even for relatively significant roll and pitch angles in the absence of surface gravity waves. However, in the presence of energetic surface waves, wave bias can contaminate or even dominate Reynolds stress measurements, even for a small tilt in sensor alignment. This effect will be discussed and assessed in Appendix B.

Estimations of TKE production rate. The rate at which energy was transferred from the mean flow to the turbulent kinetic energy through the interaction of the turbulence with the shear was estimated from the scalar product (between matrices, often called double dot product) of the Reynolds stress and the mean velocity shear:

$$
P=-\rho\left[\overline{u^{\prime} w^{\prime}} \frac{\partial \bar{u}}{\partial z}+\overline{v^{\prime} w^{\prime}} \frac{\partial \bar{v}}{\partial z}\right]
$$

where both the stress and velocity shear were estimated from the ADCP data. Because of the alignment of the ADCP to the tidal flow, being itself globally oriented in S-N direction, we would have expected the main contribution to the rate of production to come from the second term on the right-hand side of Eq. (2).

The estimate of the vertical viscosity coefficient, $A_{\mathrm{Z}}$ was calculated by the TKE production rate, $P$, dividing with a sum of mean velocity shear squared components. This 

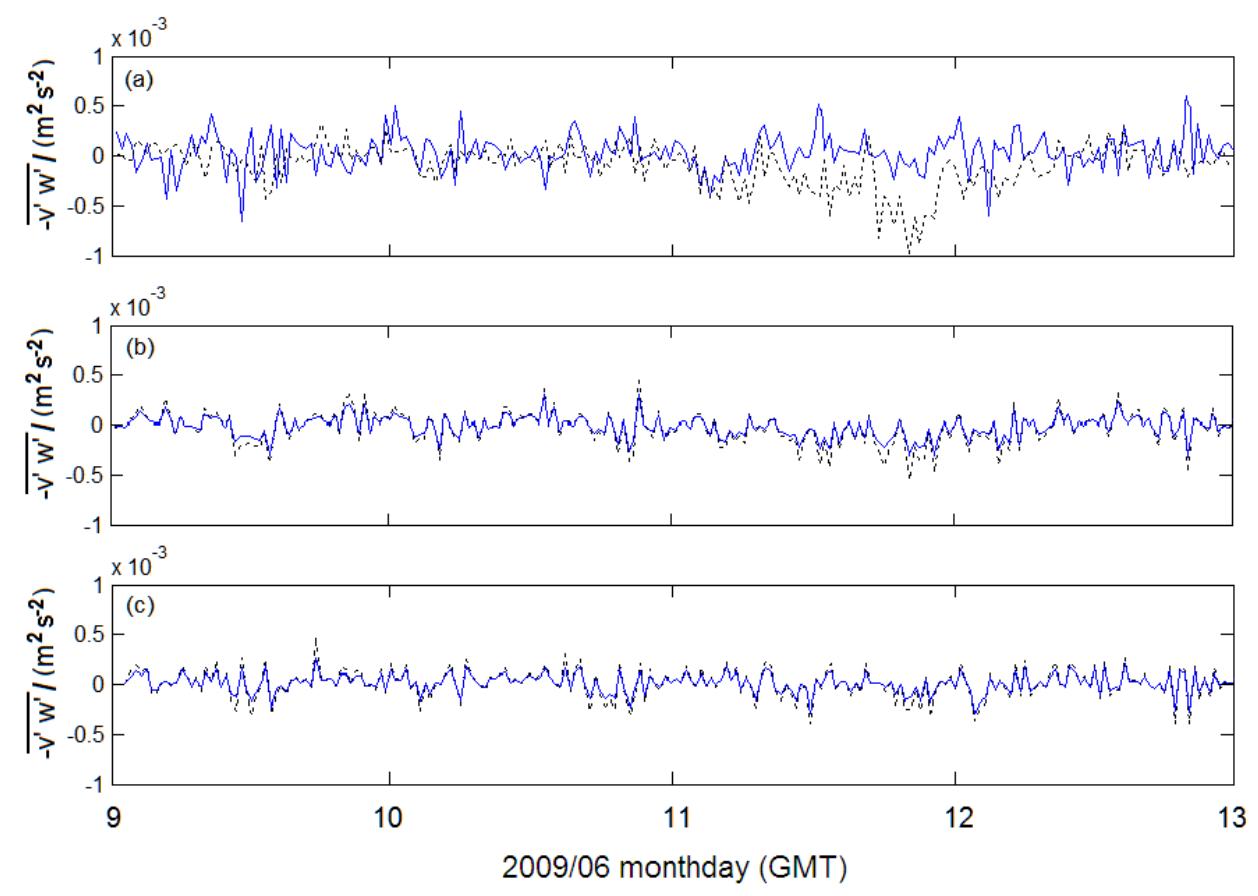

Fig. 12. Time series of Reynolds stresses calculated using the VF method (solid line) and uncorrected (dashed line) Reynolds stress time series at (a) 12, (b) 9 and (c) 7 m.a.b.

yielded

$A_{\mathrm{z}}=\frac{1}{\rho} P\left[\left(\frac{\partial \bar{u}}{\partial z}\right)^{2}+\left(\frac{\partial \bar{v}}{\partial z}\right)^{2}\right]^{-1}$

Results from Eqs. (A1)-(A3) were sensitive to the averaging time interval chosen in the Reynolds decomposition. As was mentioned above, we used an averaging interval of $20 \mathrm{~min}$, a choice justified by the examination of Reynolds stress spectra by Lu and Lueck (1999b) who revealed that comparatively low frequencies could also contribute to the stress. Technically, the high- and low-frequency velocity components were separated by fourth-order Butterworth filter at zero phase. Variances of beam velocity fluctuations were then calculated and smoothed with the same filter and averaged over $20 \mathrm{~min}$ intervals to give estimates of the Reynolds stress.

Not that despite the efficiency of the VM in assessing turbulent, quantities this method, however, can be broken down in the presence of even modest surface gravity waves, as they produce large along beam variances that become dominant near the sea surface (Rippeth et al., 2003). Therefore, removing the wave-induced bias in RS is an important task of ADCP data pre-processing. As we noted above, there are a number of methods developed for decontamination waveinduced bias of RS. In our work, for this, we have chosen the VF method described below.

\section{Appendix B}

\section{Variance Fit method}

Bias introduced by waves. In the presence of waves, the instantaneous velocity can be decomposed into a mean (e.g., $\bar{v}$ ) associated with the slowly varying flow, a component associated with the waves (e.g., $\tilde{v}$ ), and a fluctuation associated with the turbulence (e.g., $\left.v^{\prime}\right)$, so that

$$
\begin{array}{r}
v=\bar{v}+\tilde{v}+v^{\prime} \\
w=\bar{w}+\tilde{w}+w^{\prime}
\end{array}
$$

Assuming that the wave and turbulence components of the signal are uncorrelated, direct application of VM to Eq. (B1) for beams 3 and 4 according to Rosman et al. (2008) gives

$$
\frac{\overline{\left(\tilde{u}_{4}+v_{4}^{\prime}\right)^{2}}-\overline{\left(\tilde{u}_{3}+u_{3}^{\prime}\right)^{2}}}{4 \sin \theta \cos \theta}=E_{\mathrm{ws}}+E_{\text {tilt }}+E_{\text {turb }}
$$

Equation (B2) shows that the errors due to wave bias can be categorised as (1) $E_{\mathrm{ws}}$, the real wave stress $-\overline{\tilde{u} \tilde{w}}$, or (2) $E_{\text {till }}$, the error due to the interaction of wave orbital velocities and instrument tilt $\sim\left(\overline{\tilde{u}^{2}}-\overline{\tilde{w}^{2}}\right)$.

Wave bias correction. To assess the wave bias in RS, Whipple et al. (2006) proposed the VF method, which later was tested by Rosman et al. (2008) for different datasets. Based on Trowbridge's (1998) approach and extended to ADCPs by Whipple et al. (2006), this method assumes that 
wave orbital velocities are in phase along any one ADCP beam and decay with depth according to linear wave theory. The decay of wave velocity between bins chosen for differencing is determined from a fit to the vertical profile of the variance of beam velocity.

Following Whipple et al. (2006), we subtracted velocities in bins that were separated by distances greater than the correlation distance of the turbulence $(\sim 1-2 \mathrm{~m})$. In this case, we reduced the impact of waves on RS and minimised the amount of turbulent energy that was removed by the subtraction of velocity along each beam. The horizontal component of the separation was chosen to be small with respect to the wavelength of the surface waves. Then, to compute RS, we took $u_{3}$ and $u_{4}$ (similarly to $u_{1}$ and $u_{2}$ ) represented the demeaned along-beam velocities $V_{3}$ and $V_{4}$ (see Eq. 1), respectively, and were partitioned into turbulent and wave components. From the subtraction of the velocities $u_{3}$ and $u_{4}$ at $z^{(2)}$ and scaled it by an attenuation parameter $\beta$ obtained from the velocities at $z^{(1)}$, the application of VM gives an average value of the wave corrected RS component between positions 1 and 2 along beams 3 and 4 :

$$
-{\overline{v^{\prime} w^{\prime}}}^{(1-2)} \approx \frac{\overline{\Delta u_{4}^{2}}-\overline{\Delta u_{3}^{2}}}{4 \sin \theta \cos \theta\left(1+\beta^{2}\right)}
$$

where $\overline{\Delta u^{2}}$ denotes the difference of the de-meaned velocity variances. Note that the equation for $-{\overline{u^{\prime} w^{\prime}}}^{(1-2)}$ is inferred similarly.

Evaluation of the Reynolds stress using Eq. (B3) requires specification of the wave attenuation parameter, $\beta$. This is assumed to be time invariant and defined as:

$\beta \approx \sqrt{\left(\tilde{u}_{\text {beam.fit }}^{1}\right)^{2}} /\left(\tilde{u}_{\text {beam.fit }}^{2}\right)^{2}$

where $\overline{\left(\tilde{u}_{\text {beam.fit }}^{1,2}\right)^{2}}$ are the variances at $z^{(1)}$ and $z^{(2)}$ due to the wave motion. The wave variances were computed from linear wave theory using wave parameters determined by fitting a model along-beam variance profile, $\overline{\left(\tilde{u}_{\text {beam }}^{1,2}\right)^{2}}$, to the observed along-beam variance profile. For a beam axis aligned with the direction of wave propagation, the model variance profile is expressed by the following equation (Whipple et al., 2006):

$\overline{\left(\tilde{u}_{\text {beam }}\right)^{2}}=c_{1}\left[\cosh c_{2}(z+h)-\cos ^{2} \theta\right]$

where $c_{1}=H^{2} \omega^{2} / 16 \sinh ^{2} k h, c_{2}=2 k, H$ is wave height, $\omega$ is wave frequency, $k$ is the wavenumber and $h$ is the total water depth. For a beam pair oriented at some angle $\alpha$ to the direction of wave propagation, the expression for beam velocity variance as a function of depth was found by Rosman et al. (2008)

$$
\begin{aligned}
& \overline{\left(\tilde{u}_{\text {beam }}\right)^{2}}=c_{1}\left[\left(\cos ^{2} \alpha \sin ^{2} \theta+\cos ^{2} \theta\right) \cosh c_{2}(z+h)\right. \\
& \left.+\left(\cos ^{2} \alpha \sin ^{2} \theta-\cos ^{2} \theta\right)\right]
\end{aligned}
$$

Following Rosman et al. (2008), the beam velocity time series were segmented into intervals over which the flow is statistically stationary $(\Delta t$, here $10 \mathrm{~min})$, and the means are removed from the beam velocities over these time intervals. Since according to our observation the direction of the wind wave propagation relative to the instrument, for period of storms, $\alpha$, was about $15^{\mathrm{O}}$, we used this angle in Eq. (B6). Beam velocity variance, $\overline{\left(\tilde{u}_{\text {beam }}\right)^{2}}$, was calculated over each interval, and the expression in Eq. (B6) was fit to each variance profile to obtain the parameters $c_{1}$ and $c_{2}$. To remove the wave component of the beam velocity, two bins were selected at the values $z^{(1)}$ and $z^{(2)}$, centred to the height at which the Reynolds stress is required and spaced far enough apart so that the turbulence is not correlated. We have chosen $\Delta z=1.5 \mathrm{~m}$. The beam velocities at the two heights are differenced according to $\Delta u_{\text {beam }}=u_{\text {beam }}^{(1)}-\beta u_{\text {beam }}^{(2)}$. Corrected Reynolds stresses were estimated from Eq. (B3).

Figure 12 shows corrected along-shore Reynolds stress estimates obtained with the VF method and their comparison with uncorrected (Eq. A1) at 12, 9 and 7 m.a.b. for the period 9-13 June 2009 covered the first calm and storm events (Fig. 2). As seen, the wave contamination of the Reynolds stress is significant at 12 m.a.b. and the variance fit method removes the majority of this contamination leaving "pure" RS induced by shear and wave breaking turbulence. Below 9 m.a.b., levels of corrected and uncorrected Reynolds stresses track each other.

Acknowledgements. This study was supported by a CNRS-RAS Partnership Program, Grant No 21247. K.A. Korotenko acknowledges also a financial support by "Region Nord-Pas-de Calais", France for an invited research grant. We are thankful to R. Forster from the SEFAS for providing the access to the CEFAS WaveNet archive and Meteo-France for wind data.

Edited by: N. C. Wells

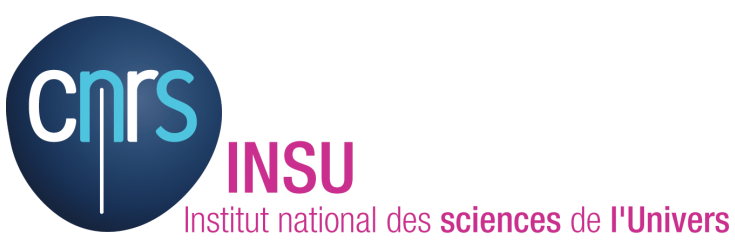

The publication of this article is financed by CNRS-INSU.

\section{References}

Ardhuin, F., Roland, A., Dumas, F., Bennis, A.-C., Sentchev, A., Forget, P., Wolf, J., Girard, F., Osuna, P., and Benoit, M.: Numerical Wave Modeling in Conditions with Strong Currents: Dissipation, Refraction, and Relative Wind, J. Phys. Ocean., 10.1175/JPO-D-11-0220.1, accepted, 2012,

Brylinski, J. M., Dupont, J. P., and Bentley, D.: Conditions hydrologiques au large du cap Griz-Nez (France); premiers resultats, Oceanol. Acta, 7, 315-322, 1984. 
Brylinski, J. M., Brunet, C., Bentley, D., Thoumelin, G., and Hilde, D.: Hydrography and phytoplankton biomass in the eastern English Channel in spring 1992, Estuar. Coast. Shelf Sci., 43, 507519, 1996.

Feddersen, F. and Williams III, A. J.: Direct estimation of the Reynolds stress vertical structure in the nearshore, J. Atmos. Oceanic Technol., 24, 102-116, 2007.

Fugate, D. C. and Chant, R. J.: Near-bottom shear stresses in a small, highly stratified estuary, J. Geophys. Res., 110, C03022, doi:10.1029/2004JC002563, 2005.

Howarth, M. J. and Souza, A. J.: Reynolds stress observations in continental shelf seas, Deep-Sea Res., II, 52, 1075-1086, 2005.

Huang, Y. X., Schmitt, F. G., Lu, Z. M., Fougairolles, P., Gagne, Y., and Liu, Y. L.: Second order structure functions in fully developed turbulence, Phys. Rev. E, 82, 026319, doi:10.1103/PhysRevE.82.026319, 2010.

Kirincich, A. R., Lentz, S. J., and Gerbi, G. P.: Calculating Reynold Stresses from ADCP Measurements in the Presence of Surface Gravity Waves Using the Cospectra-Fit Method, J. Atmos. Oceanic Technol., 27, 889-907, 2010.

Korotenko, K. A. and Sentchev, A. V.: On the formation of anomalies in the ichthyoplankton concentration field along the French coast in the eastern English Channel, Oceanology, 44, 644-653, 2004.

Korotenko, K. A. and Sentchev, A. V.: Effects of the particle migration on the features of their transport by tidal currents in the region of freshwater influence, Oceanology, 48, 672-684, 2008.

Korotenko, K. A. and Sentchev, A. V.: Study turbulence in shallow tidal coastal zone, Oceanology, 51, 1-14, 2011.

Lohrmann, A., Hackett, B., and Roed, L. P.: High resolution measurements of turbulence, velocity, and stress using a pulse-topulse coherent sonar, J. Atmosph. Oceanic Technol., 7, 19-37, 1990.

Lu, Y. and Lueck, R. G.: Using a broadband ADCP in a tidal channel. Part I: Mean flow and shear, J. Atmos. Ocean. Techn., 16, 1556-1567, 1999a.

Lu, Y. and Lueck, R. G.: Using a broadband ADCP in a tidal channel. Part II: Mean flow and shear, J. Atmos. Ocean. Techn., 16, 1568-1579, 1999b.

Lu, Y., Lueck, R. G., and Huang, D.: Turbulence Characteristics in a Tidal Channel, J. Geophys. Res., 30, 855-867, 2000.

Nidzieko, N. J., Fong, D. A., and Hench, J. L.: Comparison of Reynolds stress estimates derived from standard and fastping ADCPs, J. Atmosph. Ocean. Technol., 23, 854-861, 2006.

Peters, H.: Observations of stratified turbulent mixing in an estuary. Neap-to-spring variations during high river run-off, Estuar. Coast. Shelf Sci., 45, 69-88, 1997.

Peters, H. and Johns, W. E.: Bottom layer turbulence in the Red Sea outflow plume, J. Phys. Oceanogr., 36, 1763-1785, 2006.

Peters, H., Lee, C. M., Orlic, M., and Dorman, C. E.: Turbulence in the wintertime northern Adriatic Sea under strong atmospheric forcing, J. Geophys. Res., 112, C03S09, doi:10.1029/2006JC003634, 2007.

Prandle, D., Losch, S. G., and Player, R.: Tidal flow through the Straits of Dover, J. Phys. Oceanogr., 23-37, 1993.

Rippeth, T. P., Williams, E., and Simpson, J. H.: eynolds stress and turbulent energy production in a tidal channel, J. Phys. Oceanogr., 32, 1242-1251, 2002.
Rippeth, T. P., Simpson, J. H., Williams, E., and Inall, M. E.: Measurement of the rates of production and dissipation of turbulent kinetic energy in an energetic tidal flow: Red Wharf Bay revisited, J. Phys. Oceanogr., 33, 1889-1901, 2003.

Rosman, J. H., Hench, J. L., Koseff, J. R., and Monismith, S. G.: Extracting Reynolds stresses from acoustic Doppler current profiler measurements in wave dominated environments, J. Atmos. Oceanic Technol., 25, 286-306, 2008.

Schmitt, F. G., Huang, Y., Lu, Z., Liu, Y., and Fernandez, F.: Analysis of velocity fluctuations and their intermittency properties in the surf zone using empirical mode decomposition, J. Mar. Syst., 77, 473-481, 2009.

Seim, H.: Reynolds stress measurements in a short tidal inlet. In Proc. 2nd Meeting on the Physical Oceanography of Sea Straits, Villefranche, 199-202, 15-19 April 2002.

Sentchev, A. and Korotenko, K. A.: Stratification and tidal current effects on larval transport in the eastern English Channel: observations and 3D modelling, Environ. Fluid Mech., 4, 305-331, 2004.

Sentchev, A. and Korotenko, K. A.: Dispersion processes and transport patterns in the ROFI of eastern English Channel derived from a particle tracking method, Cont. Shelf Res., 25, 22932308, 2005.

Sentchev, A. and Yaremchuk, M.: VHF radar observations of surface currents off the northern Opal coast in the eastern English Channel, Cont. Shelf Res., 27, 2449-2464, 2007.

Shaw, W. J. and Trowbridge, J. H.: The measurement of near-bottom turbulent fluxes in the presence of energetic wave motions, J. Atmosph. Ocean. Technol., 18, 1540-1557, 2001.

Souza, A. J. and Howarth, M. J.: Estimates of Reynolds stress in a highly energetic shelf sea, Ocean Dynam., 55, 490-498, 2005.

Stacey, M. T., Monismith, S. G., and Burau, J. R.: Measurements of Reynolds stress profiles in unstratified tidal flow, J. Geophys. Res., 104, C5, 10933-10949, 1999.

Tennekes, H. and Lumley, J. L.: A first course in turbulence, MIT Press, Cambrige, MA, USA, 1972.

Terray, E. A., Donelan, M. A., Agarwal, Y. C., Drennan, W. M., Kahma, K. K., Williams III, A. J., Hwang, P. A., and Kitaigorodskii, S. A.: Estimate of kinetic energy dissipation under breaking waves, J. Phys. Oceanogr., 26, 792-807, 1996.

Trowbridge, J. H.: On a technique for measurement of turbulent shear stress in the presence of surface waves, J. Atmos Ocean. Technol., 15, 290-298, 1998.

Trowbridge, J. H. and Elgar, S.: Spatial scales of stress-carrying nearshore turbulence, J. Phys. Oceanogr., 33, 1122-1128, 2003.

Vantrepotte, V., Brunet, C., Mériaux, X., Lécuyer, E., Vellucci, V., and Santer, R.: Bio-optical properties of coastal waters in the Eastern English Channel, Est. Coast. Shelf Sci., 72, 201-212, 2007.

Wavenet archive: http://www.cefas.co.uk/wavenet, last access: 18 April 2009.

Whipple, A. C., Luettich, R. A., and Seim, H. E.: Measurements of Reynolds stress in a wind-driven lagoonal estuary, Ocean Dynam., 56, 169-185, 2006.

Willes, P. J., Rippeth, T. P., Simpson, J. H, and Hendricks, P. J.: A novel technique for measuring the rate of turbulent dissipation in the marine environment, Geophys. Res. Lett., 33, L21608, doi:10.1029/2006GL027050, 2006. 